\title{
EXTRAÇÃO DE $\beta$-CAROTENO DE CENOURAS: UMA PROPOSTA PARA DISCIPLINAS EXPERIMENTAIS DE QUÍMICA
}

\author{
Maria Luiza Zeraik e Janete Harumi Yariwake* \\ Instituto de Química de São Carlos, Universidade de São Paulo, CP 780, 13560-970 São Carlos - SP, Brasil
}

Recebido em 12/3/07; aceito em 25/10/07; publicado na web em 9/4/08

\begin{abstract}
EXTRACTION OF $\beta$-CAROTENE FROM CARROTS: A PROPOSAL FOR EXPERIMENTAL COURSES IN CHEMISTRY. This paper reports on the development of a simple and fast procedure for $\beta$-carotene extraction from carrots and its quantification by UV/Vis spectroscopy. Carotenoids extracted from carrots may also be used as alternative reagents for TLC (thin layer chromatography) detection of natural compounds with antioxidant properties, replacing the commercial p.a. grade $\beta$-carotene. Although this reagent had around $10 \% \beta$-carotene, it proved to be as efficient for TLC analysis as the commercial p.a. grade $\beta$ carotene. This practice is a useful alternative for teaching undergraduate organic chemistry laboratory classes.
\end{abstract}

Keywords: $\beta$-carotene; antioxidant; TLC.

\section{INTRODUÇÃO}

No funcionamento normal do organismo humano ocorre uma série de reações químicas, com o objetivo de produzir energia. Em algumas destas reações são produzidos os chamados "radicais livres" ou simplesmente, "radicais", os quais são instáveis e reativos, reagindo rapidamente com diversos compostos e alvos celulares, podendo danificar DNA, proteínas, carboidratos e lipídeos. Por este motivo, os radicais estão envolvidos em diversas doenças que afetam o ser humano. ${ }^{1-3}$

Antioxidantes são substâncias capazes de reagir com os radicais livres e neutralizá-los, apresentando como efeitos benéficos o retardamento do processo de aterosclerose, a prevenção da obstrução das artérias e a redução do processo de morte celular em vários órgãos como o cérebro, rins, pulmões e pele., ${ }^{4,5}$

Os antioxidantes naturais estão recebendo maior atenção por poderem representar uma alternativa às substâncias sintéticas, como o butil-hidroxi-tolueno (BHT, 2,6-bis (1,1-dimetiletil)-4-metilfenol) ou o butil-hidroxi-anisol (BHA, mistura dos isômeros 2-terc-butil4-metoxifenol e 3-terc-butil-4-metoxifenol), usadas como conservantes alimentares. ${ }^{6}$ Uma das mais importantes fontes naturais de antioxidantes são as plantas que contêm compostos fenólicos, como por exemplo os flavonóides, os quais podem ocorrer em todas as partes dos vegetais: tronco, raízes, folhas, flores, frutas e sementes. ${ }^{7-9}$

A análise por cromatografia em camada delgada (CCD) utilizando $\beta$-caroteno como revelador tem sido amplamente empregada na detecção de produtos naturais com propriedade antioxidante. ${ }^{10-14}$ Esta técnica apresenta muitas vantagens como a fácil execução e compreensão, simplicidade, versatilidade e baixo custo.

O $\beta$-caroteno é um carotenóide que atua como antioxidante devido às suas ligações duplas conjugadas, que são suscetíveis à oxidação sob ação de luz ou oxigênio (Figura 1). ${ }^{7}$ Carotenóides são pigmentos naturais presentes em várias frutas e vegetais, como por exemplo, cenoura, tomate, espinafre, laranja e pêssego. Dos mais de 600 carotenóides existentes na natureza, aproximadamente 20 estão presentes em tecidos e no plasma humano, dos quais

*e-mail: janete@iqsc.usp.br

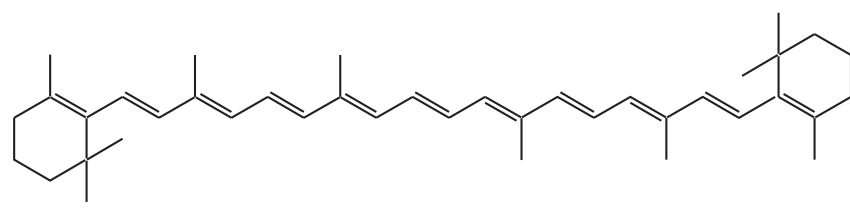

Figura 1. Estrutura do $\beta$-caroteno

apenas 6 em quantidades significativas: $\alpha$-caroteno, $\beta$-caroteno, $\beta$ criptoxantina, licopeno, luteína e zeaxantina. O metabolismo humano não é capaz de produzir estas substâncias e depende da alimentação para obtê-las, pois muitas delas se convertem em vitamina A no organismo., ${ }^{9,15}$

Os espectros de absorção no UV-Visível dos carotenóides têm um perfil característico entre 400 e $500 \mathrm{~nm}$, com $\lambda_{\max }$ por volta de $450 \mathrm{~nm}$ e normalmente duas bandas menores de cada lado. A posição exata dos máximos de absorção varia de pigmento para pigmento e é suficientemente diferente para a identificação de cada carotenóide. $^{7}$ As colorações variam desde o amarelo, passando pelo laranja, até o vermelho intenso, e resultam das ligações duplas conjugadas na estrutura mais freqüente, do tipo $\mathrm{C}_{40}$.

A literatura relata diversos exemplos de trabalhos que descrevem a extração de carotenóides e flavonóides de alimentos como uma proposta para aulas experimentais em Química. ${ }^{16-20}$ Diferenciando-se dos demais, este trabalho propõe um procedimento rápido, de fácil execução e baixo custo para revelação por CCD de substâncias com propriedade antioxidante. Assim, neste trabalho é apresentado o desenvolvimento, quantificação, testes de eficácia na detecção por CCD de substâncias antioxidantes e validade da solução de carotenóides extraídos de cenouras. Este experimento pode ser executado integralmente ou parcialmente em aulas práticas de Química Orgânica ou de Análise Instrumental.

\section{PARTE EXPERIMENTAL}

\section{Extração do $\beta$-caroteno das cenouras}

As cenouras utilizadas foram compradas no comércio local da cidade de São Carlos, SP. Foram utilizadas 5 cenouras de tamanho e grossura variadas (perfazendo $\sim 500 \mathrm{~g}$ ). A camada externa da ce- 
noura foi raspada com uma faca e a seguir cortada em rodelas.

Uma amostra com aproximadamente $80 \mathrm{~g}$, obtida por quarteamento, ${ }^{21}$ foi batida em liquidificador e, em seguida, transferida para um cadinho e macerada com $50,0 \mathrm{~mL}$ de éter de petróleo. A solução resultante foi filtrada e, em seguida, extraída mais uma vez com 50,0 mL de éter de petróleo. Após filtração, as soluções combinadas foram evaporadas num rotaevaporador. Após retirada do solvente, o extrato de cenouras foi pesado e depois dissolvido em diclorometano, ajustando-se a concentração final para $0,2 \mathrm{~g}$ extrato $\mathrm{L}^{-1}$. As extrações foram realizadas em quintuplicata. Estas soluções foram utilizadas como reveladores nas análises por $\mathrm{CCD}$ e também submetidas às análises espectrofotométricas.

\section{Análise por UV-Vis do extrato de cenouras e do $\beta$-caroteno}

Os espectros de absorção no UV-Vis foram obtidos em um espectrofotômetro Hitachi U-3210. Para a determinação do "prazo de validade" do extrato de cenouras e da solução de $\beta$-caroteno p.a., ambos na concentração de $0,2 \mathrm{~g} \mathrm{~L}^{-1} \mathrm{em}$ diclorometano, foram realizadas medidas de absorbância das soluções a 436 nm (comprimento de onda utilizado seguindo o Método Oficial da AOAC). ${ }^{22}$

Foi obtido um espectro por semana, durante 8 semanas, sempre no mesmo dia da semana e por volta do mesmo horário, com a mesma solução de extrato de cenouras. O mesmo teste, nas mesmas condições, foi repetido com a solução de $\beta$-caroteno p.a.

Quantificação dos carotenóides totais (expresso em $\boldsymbol{\beta}$-caroteno) do extrato de cenouras

A quantificação foi realizada pelo método do padrão externo, utilizando $\beta$-caroteno p.a. como referência. Para construção da curva analítica, inicialmente foi preparada uma solução de $\beta$-caroteno p.a. com concentração de $0,2 \mathrm{~g} \mathrm{~L}^{-1}$ em diclorometano. A partir desta solução foram preparadas por diluição, soluções de concentrações: 1,$26 ; 2,52 ; 3,78 ; 5,04$ e $6,30 \mathrm{mg} \mathrm{L}^{-1}$. A concentração de carotenóides totais do extrato de cenouras foi calculada pela equação da reta, obtida através do gráfico da curva analítica.

\section{Análise por CCD}

Em uma placa de CCD foram aplicados $3 \mu \mathrm{L}$ da solução dos padrões de flavonóides com propriedade antioxidante, quercetina e rutina (Merck), ambos na concentração de 1,0 $\mathrm{mg} \mathrm{mL}^{-1}$ de metanol. A placa foi eluída com uma mistura de acetato de etila/ácido fórmico/água na proporção de 6:1:1 v/v. ${ }^{23}$ Após a secagem, a placa de CCD foi borrifada com a solução de extrato de cenouras ou de $\beta$-caroteno p.a. (Sigma), ambos na concentração $0,2 \mathrm{~g} \mathrm{~L}^{-1} \mathrm{em}$ diclorometano. A concentração e o solvente foram utilizados de acordo com as informações obtidas da literatura. ${ }^{13}$ As placas foram deixadas à temperatura ambiente até o descoramento total da cor laranja do revelador e o aparecimento de manchas alaranjadas características de substâncias com atividade antioxidante.

\section{RESULTADOS E DISCUSSÃO}

Foram testados vários solventes para a extração dos carotenóides da cenoura (éter de petróleo, metanol e também misturas em diferentes proporções de éter de petróleo/metanol e éter de petróleo/água), sendo que foi obtido melhor rendimento utilizando apenas éter de petróleo. A partir de 5 amostras de cenouras ( $80 \mathrm{~g}$ cada), a massa média do extrato de cenouras foi de $(13,1 \pm 1,2) \mathrm{mg}$, correspondendo ao rendimento médio de $(0,016 \pm 0,001) \%$.

A partir dos extratos foram preparadas soluções de concentra- ção $0,2 \mathrm{~g} \mathrm{~L}^{-1}$ em diclorometano para quantificação por UV-Vis dos carotenóides totais e para utilização como revelador em CCD.

\section{Análise por UV-Vis}

Foi feita a comparação dos espectros UV-Vis do extrato de cenouras com os do $\beta$-caroteno p.a. Os espectros do extrato de cenouras e do $\beta$-caroteno p.a. apresentaram grande similaridade (Figura 2), sendo observada uma banda com $\lambda_{\text {máx }} \sim 460 \mathrm{~nm}$, característica das ligações duplas conjugadas do $\beta$-caroteno. ${ }^{7}$
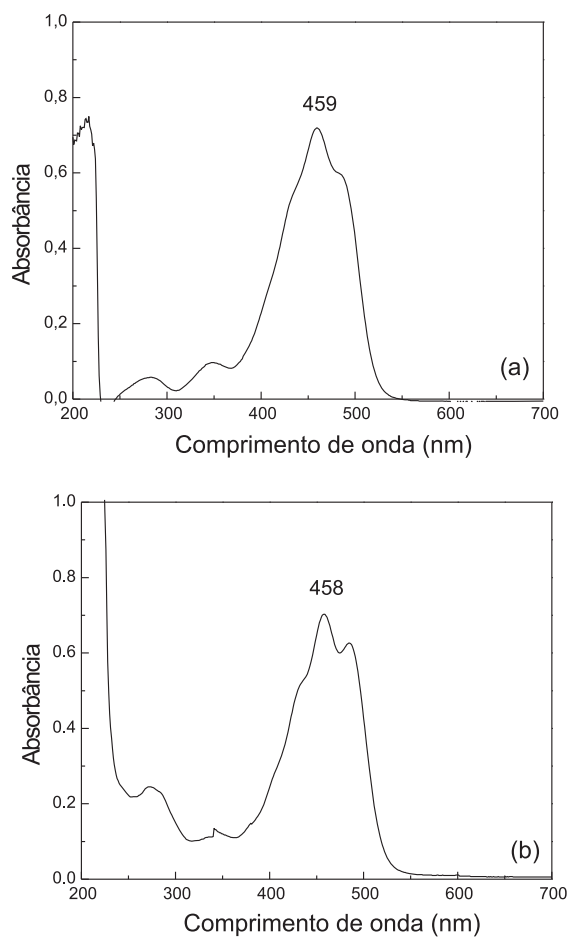

Figura 2. Espectro de absorção no UV-Vis (solvente: diclorometano). (a) $\beta$ caroteno p.a. e (b) extrato de cenouras em diclorometano

Foram obtidos também espectros no UV-Vis ao longo de várias semanas para verificar o "prazo de validade" da solução de extrato de cenouras. Comparando com o espectro do $\beta$-caroteno p.a. (Figura 3a), foi observada a alteração da banda correspondente ao $\beta$ caroteno $\left(\lambda_{\text {máx }} \sim 450 \mathrm{~nm}\right.$, Figura $3 \mathrm{~b}$ ) indicando que o extrato de cenouras perde suas propriedades e eficácia na detecção de substâncias antioxidantes em aproximadamente 2 meses, mesmo armazenado na geladeira e protegido da luz.

O gráfico do decaimento da absorbância (Figura 4) mostra a maior estabilidade do extrato de cenouras em relação ao $\beta$-caroteno p.a. e não foi possível determinar o tempo no qual a concentração inicial de $\beta$-caroteno decai pela metade. Para a solução de $\beta$ caroteno p.a. o tempo observado foi de 2 semanas.

A quantificação do extrato de cenouras é importante para a padronização deste como revelador alternativo em CCD para substâncias antioxidantes. A Tabela 1 mostra os dados obtidos para construção da curva analítica, utilizando o $\beta$-caroteno p.a. como padrão. A concentração de carotenóides totais do extrato de cenouras foi calculada pela equação da reta $(A=0,003+136,791 \mathrm{C}$ onde A: absorbância, $\mathrm{C}$ : concentração de $\beta$-caroteno em $\left.\mathrm{g} \mathrm{L}^{-1} ; \mathrm{r}=1\right)$. Pôde-se verificar que o extrato de cenouras apresenta $10 \%$ de carotenóides totais (Tabela 2) e, portanto, que esta solução é 10 vezes mais diluída que a descrita na literatura para o $\beta$-caroteno p.a. utilizado como revelador para CCD. ${ }^{13}$ 

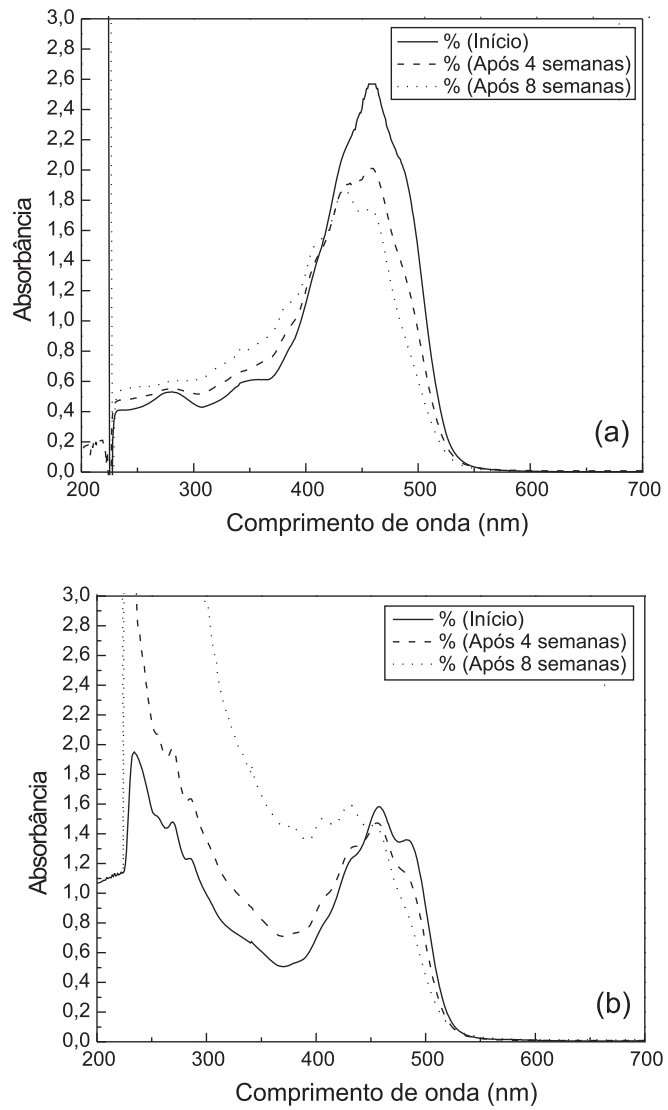

Figura 3. Determinação por espectroscopia de absorção no UV-Vis (solvente: diclorometano) do "prazo de validade". (a) $\beta$-caroteno p.a. e (b) extrato de cenouras

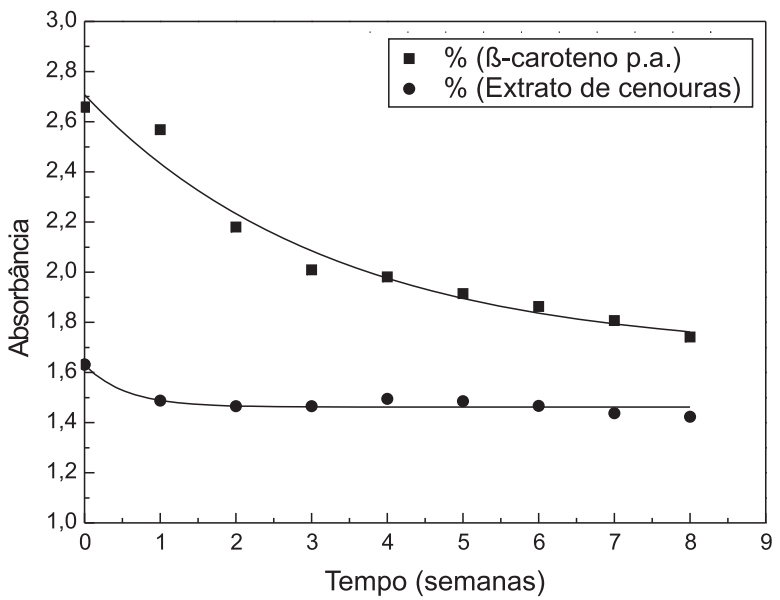

Figura 4. Gráfico do decaimento da absorbância em $\lambda=436 \mathrm{~nm}$ do $\beta$-caroteno p.a. e do extrato de cenouras
Tabela 1. Dados utilizados para construção da curva analítica do $\beta$-caroteno

\begin{tabular}{lcc}
\hline $\begin{array}{c}\text { Solução } \\
\text { de } \beta \text {-caroteno }\end{array}$ & $\begin{array}{c}\text { Absorbância }(\lambda=436 \mathrm{~nm}) \\
\pm \text { desvio padrão }\end{array}$ \\
\hline 1 & 1,26 & $0,175 \pm 0,003$ \\
2 & 2,52 & $0,345 \pm 0,003$ \\
3 & 3,78 & $0,534 \pm 0,004$ \\
4 & 5,04 & $0,689 \pm 0,004$ \\
5 & 6,30 & $0,855 \pm 0,005$ \\
\hline
\end{tabular}

\section{Análise por CCD}

Este teste teve como objetivo comparar o extrato de cenouras com a solução de $\beta$-caroteno p.a., a fim de verificar se o primeiro também possui a mesma propriedade de revelar substâncias com propriedades antioxidantes.

Após borrifar a placa de CCD contendo os padrões de flavonóides com revelador de $\beta$-caroteno p.a., foi observada uma coloração laranja intensa, enquanto que a placa borrifada com o extrato de cenouras apresentou coloração laranja clara. Após $2 \mathrm{~h}$ à temperatura ambiente, foi observado o descoramento total da cor laranja do extrato, ou seja, a oxidação do $\beta$-caroteno, e o aparecimento das manchas características de cada padrão. $O$ tempo de descoramento do $\beta$-caroteno p.a. foi de cerca de $20 \mathrm{~h}$. Foi observada coloração mais intensa na placa revelada com $\beta$-caroteno p.a. que na placa revelada com extrato de cenouras; no entanto, a diferença de intensidade da coloração das manchas dos padrões de rutina e quercetina foi pequena.

Foi feita a comparação dos custos das duas soluções, considerando o quilo da cenoura a $\mathrm{R} \$ 0,40$ e sem incluir o custo do solvente necessário (100,0 mL para ambas): $\mathrm{R} \$ 1,25$ e $\mathrm{R} \$ 0,03$ para a solução de $\beta$-caroteno p.a e de extrato de cenouras, respectivamente. Como o extrato de cenouras demonstrou ser eficaz para a revelação em CCD, apesar de conter apenas $10 \%$ de $\beta$-caroteno, a comparação do custo final das soluções utilizadas na revelação é portanto mais favorável ao extrato de cenouras.

\section{Resumo das atividades a serem desenvolvidas pelos estu- dantes}

Deve ser solicitado aos estudantes que executem as seguintes atividades: a. extração de carotenóides das cenouras; b. preparo da solução-padrão de $\beta$-caroteno p.a. e realizar as diluições necessárias. Cálculo da concentração de $\beta$-caroteno em cada solução preparada por diluição; c. obtenção dos espectros no UV-Vis das soluções de $\beta$-caroteno p.a. e do extrato de cenouras, e comparação com os dados da literatura; d. obtenção da curva analítica (concentração de $\beta$-caroteno p.a. versus absorbância) e determinação da concentração de $\beta$-caroteno no extrato de cenouras; e. análise dos padrões de flavonóides (rutina e quercetina) por $\mathrm{CCD}$, revelação com a solução de extrato de cenouras e também com $\beta$-caroteno p.a., para posterior comparação das placas.

Tabela 2. Resultados da análise quantitativa do extrato de cenouras

\begin{tabular}{lccccc}
\hline Extração & $\begin{array}{c}\text { Massa de cenoura } \\
(\mathrm{g})\end{array}$ & $\begin{array}{c}\text { Massa de extrato } \\
(\mathrm{mg})\end{array}$ & $\begin{array}{c}\text { Absorbância } \\
(\lambda=436 \mathrm{~nm})\end{array}$ & $\begin{array}{c}\text { Concentração } \\
\left(\mathrm{g} \mathrm{L}^{-1}\right)\end{array}$ & $\begin{array}{c}\text { Carotenóides totais }(\%) \\
{[\text { Expresso em } \beta \text {-caroteno] }}\end{array}$ \\
\hline 1 & 80,423 & 8,3 & 0,5537 & 0,020 & 12,1 \\
2 & 80,550 & 10,2 & 0,4597 & 0,017 & 8,3 \\
3 & 80,408 & 10,0 & 0,5213 & 0,019 & 9,5 \\
\hline
\end{tabular}




\section{Destaques didáticos}

a. refletir sobre a importância de substâncias orgânicas extraídas de alimentos e sua contribuição para a saúde; $b$. a associação da cor da solução de carotenóides com o espectro de absorção no UV-Vis deve ser realizada, possibilitando uma melhor compreensão química do experimento; $c$. o estudo do procedimento cromatográfico (CCD); $d$. também podem ser abordados testes estatísticos com a realização das medidas em triplicata (cálculo da média e desvio-padrão).

\section{CONCLUSÕES}

O presente estudo mostrou que o extrato de cenouras pode ser uma boa alternativa de revelação de substâncias com propriedades antioxidantes, devido à simplicidade, praticidade, rapidez e baixo custo, com resultados similares aos do $\beta$-caroteno p.a.

Este experimento pode ser uma alternativa para aulas experimentais de Química Orgânica ou Análise Instrumental, pois é uma prática simples, de baixo custo, que requer em torno de 3-4 h e que aborda muitos temas importantes em Química. Além disso, considerando somente a etapa de extração, que não necessita de instrumentação sofisticada, pode ser realizada inclusive no ensino médio com algumas adaptações, utilizando materiais de baixo custo e de fácil aquisição, incluindo a separação dos carotenóides utilizando uma coluna cromatográfica com pó de giz como fase estacionária $^{24} \mathrm{e}$ secagem do extrato à temperatura ambiente. De forma opcional, o experimento também pode ser realizado com outros alimentos que contenham $\beta$-caroteno (por exemplo, abóbora, mamão, manga, espinafre, entre outros), por diferentes equipes de estudantes, com o objetivo de posterior comparação dos resultados.

\section{AGRADECIMENTOS}

À FAPESP (Proc. 02/00493-2 e 03/14005-2) e ao CNPq (Proc. 300912/2005-6) pelo suporte financeiro.Os autores também agradecem ao Sr. B. M. dos Santos e à Dra. R. Colombo pela colaboração.

\section{REFERÊNCIAS}

1. Cerqueira, F. M.; de Medeiros, M. H. G.; Augusto, O.; Quim. Nova 2007, $30,441$.

2. Antolovich, M.; Prenzler, P. D.; Patsalides, E.; McDonald, S.; Robards, K.; Analyst 2002, 127, 183.

3. Gutteridge, J. M. C.; Halliwell, B.; Antioxidants in Nutrition, Health, and Disease, Oxford University Press: Oxford, 1994, p. 143.

4. Huang, D.; Prior, R. L.; J. Agric. Food Chem. 2005, 53, 1841.

5. Ramalho, V. C.; Jorge, N.; Quim. Nova 2006, 29, 755.

6. Maga, J. A.; Tu, A. T.; Food Additive Toxicology, Marcel Dekker: New York, 1995, p. 542.

7. Harbone, J. B.; Phytochemical methods: A guide to modern techniques of plant analysis, $2^{\text {nd }}$ ed., Chapman and Hall: London, 1984, p. 55-136.

8. Jovanovic, S. V.; Steenken, S.; Tosic, M.; Marjanovic, B.; Simic, M. G.; J. Am. Chem. Soc. 1994, 116, 4846.

9. Packer, L.; Hiramatsu, M.; Yoshikawa, T.; Antioxidant food supplements in human health, Academic Press: Orlando, 1999, p. 183-269.

10. Pratt, D. E.; Miller, E. E.; J. Am. Oil Chem. Soc. 1984, 61, 1064.

11. Silva, D. H. S.; Pereira, F. C.; Yoshida, M.; Phytochemistry 2001, 57, 437.

12. Koleva, I. I.; Beek, T. A.; Linssen, J. P. H.; Evstatieva, L. N.; Phytochem. Anal. 2002, 13, 18.

13. Corsino, J.; Silva, D. H. S.; Zanoni, M. V. B.; Bolzani, V. da S.; França, S. C.; Pereira, A. M.; Furlan, M.; Phytother. Res. 2003, 17, 913.

14. Silva, V. C.; Lopes, M. N.; Bolzani, V. da S.; Quim. Nova 2006, 29, 493.

15. Almeida, L. B.; Penteado, M. V. C.; Rev. Farm. Bioq. 1987, nº 23, 133.

16. Costa, C. L. S.; Chaves, M. H.; Quim. Nova 2005, 28, 149.

17. Silva, L. B.; Alles, I. M.; Morel, A. F.; Daicol, I. I.; Química Nova na Escola 2006, $\mathrm{n}^{\circ} 23,52$.

18. Okumura, F.; Soares, M. H. F. B.; Cavalheiro, E. T. G.; Quim. Nova 2002, 25,680 .

19. Curtright, R. D.; Rynearson, J. A.; Markwell, J.; J. Chem. Educ. 1994, 71 , 682.

20. Ramos, L. A.; Cavalheiro, C. C. S.; Cavalheiro, E. T. G.; Quim. Nova 2006 , $29,1114$.

21. Simões, C. M. O.; Schenkel, G. G.; Mello, J. C. P.; Farmacognosia: da planta ao medicamento, $1^{\text {a }}$ ed., UFSC: Porto Alegre, 1999, p. 201.

22. Association of Official Analytical Chemists Em Official methods of analysis; $16^{\text {th }}$ ed., Cunnif, P., ed.; AOAC: Washington D.C.,1995.

23. Brasseur, T.; Wauters, J. N.; Angenot, L.; J. Chromatogr. 1988, 437, 260.

24. Oliveira, A. R. M.; Simonelli, F.; Marques, F. A.; Química Nova na Escola $1998, n^{\circ} 7,37$. 